\title{
Manual Potter's Wheel Efficiency in Ceramics Production in Nigeria
}

\author{
Okewu Ebute Jonathan \\ Department of Visual and Creative Arts, Federal University Lafia, Nassarawa State
}

\begin{abstract}
This paper review how effective the manual wheel have been put into use for optimum productivity in the face epileptic power supply in the country. It examines the art of throwing, types of wheels used in the specialisation for production. The advantages and disadvantages of each types of wheels and how convenient their uses are is also examined. The central issue is the rate of power supply in Nigeria and the need to encourage less emphasis on the electric wheels that might not be working well for a depressed economy.
\end{abstract}

\section{Introduction}

To create pottery and ceramics, you will need a potter's wheel and the physical ability to operate an electric or kick wheel-operated version of the machine (Dodrill, 2013). Pottery are activities that satisfies the intellectual interest of the maker as well as the need to make. Making is as a matter of fact a fundamental part of being human in life (Mamza, 2012). In every area of human endeavours, maximum productivity is expected to be able to meet up with the demands of the teaming populace whether a manual or an automatic machine is in use. The field of ceramics is one that cannot be lacking in this aspect. To be able to reasonably meet the needs of the consumer, a potter must be up and doing especially with the difficult (lack of amenities for the growth of industries) environment a potter has found his or herself. whether a manual or an electric potter's wheel is in use, maximum productivity is required. The invention of the electric potter's wheel is an excellent innovation in ceramics not only has it positive sides but also has its negative sides especially in a growing society where electricity to always power the electric wheels is scarcely available to the detriment of the potter.

\section{Throwing Method of Pottery Production}

Throwing is the technique of making an object from clay on a pottery wheel. While we have electric pottery wheels today, a manual wheel, called a Kick wheel can be used. Historically pots were made on a hand turned wheel - a turntable. They were used to make pots from speeding up the process of coiling before moving to the method we know as throwing used today (Evans, 2009). Wheel throwing to make clay objects was developed in China at least as early as $3500 \mathrm{BC}$. This involves centering a ball of clay on a table that is turned by kicking a weighted wheel, or operating a treadle. The form is shaped by the potters hands, but is perfectly symmetrical, because of the turning of the wheel as he shapes the clay. Throwing is the method most commonly used today for handmade ceramics. (Jirousek, 1995 ). This techniques is very much mechanical. A wheel that is mainly made for making pots is used. The wheel has very many models and sizes. In most cases, the wheel turns in an anti-clockwise direction and the speed of the wheel can be regulated from time to time to suit the stage of production. This technique requires a lot of patience and determination. (Gukas and Datiri 2001). The potter's wheel can be used for mass production, although often it is employed to make individual pieces. Wheel work takes a lot of technical ability, but a skilled potter can produce many virtually identical plates, vases or bowls in a day. Because of its nature, wheel work can only be used to initially create items with radial symmetry on a vertical axis. (Ortiz, 2010). Throwing method of pottery which was introduced due to the increase in number of the populace, has the capacity of producing more wares as compared to the earlier traditional hand built method. Throwing method is more practiced today in the specialisation because of the accuracy, efficiency, time saving and mass production it offers.

\section{Manual Wheels}

A kick wheel is a heavy potter's wheel propelled by a person's foot kicking the heavy cylinder at the bottom. Some beginners find it easier to control the speed of a kick wheel than it is to control the speed of an electric wheel. Kick wheels are extremely durable and long lasting. They are also very heavy. They are probably best suited for a dedicated ceramics studio where they will remain in one location. (Specialty, 2013). With this a pot could be turned around much more easily and quickly. The pot making technique in Mesopotamia now gradually changed during the third millennium $\mathrm{BC}$ as the more potters adopted the turntable for making and decorating. (Bryant, 2013). The development of the slow, or hand-turned, wheel as an adjunct to pottery manufacture led eventually to the introduction of the kick wheel, rotated by foot. By the 18th Century the wheel 
was no longer turned by the potter's foot but by small boys apprenticed to the potter, and since the 19th century the motive power has been mechanical. (Hellmold, 2001). A foot-operated kick-wheel allows the potter to insert energy while continuing the throwing activity. Given skilled potters' capacity to effectively separate foot and hand movements, one may reasonably expect the regulation of rotation speed to be close to optimal for reasons of energy efficiency. (Gandon, 2013). The manual wheel though usually heavy but more easier to control and more comfortable learning how to throw with. In a developing society where electric power is usually scarce, one would expect that the manual wheels should be put more into practise both for professionals and beginners for optimum production. According to Jones (2010), there are basically two types of foot-powered wheels

- Kick wheels

- Treadle wheels.

Jones further explain the Kick wheel and Treadle wheel as follows;

Kick Wheel; The kick wheel works by kicking the flywheel in a specific rhythm. This powers the wheel head, it also utilizes a heavy flywheel that stores energy as it speeds up when propelled by your foot, while the treadle wheel utilizes a lever and cam mechanism that turns a shaft with a weighted fly- wheel. Operating a footpowered wheel takes a little practice and coordination, but potters who use them swear by the relaxed rhythm and pace of their throwing as well as their intimate connection to the throwing process. The main components of most kick wheels are as follows:

- Most basic kick wheels are constructed with a steel frame

- Most come with an adjustable seat

- Reinforced cast concrete flywheel

- Cast metal wheel head

- Wood metal or composite work surface.

- Even though you can power the wheels by foot, some models come with an electric motor option. With flywheels weighing between 120 and 140 pounds, the motors easily maintain momentum after the flywheel is turning

Treadle Wheels; The treadle pottery wheel is a more recently developed pottery wheel. It is easier to operate than the kick pottery wheel because the left foot is used to rock a treadle, rather than in a kicking motion. Treadle wheels, which rely on a foot-powered treadle mechanism to drive a flywheel, were once common in English and American potteries and more recently mass produced for both school and private studio. The most common version now available is a sit down version based on a designed refined by Bernard Leach at the beginning of the 20th century. The so-called Leach wheel is legendary among potters who prefer the nonelectric wheel, probably because of the comfort achieved even throwing for long stretches of time.

The manual wheel has gotten different types for the comfort of potters. While different types will be more comfortable to different potters, it important to note that over time the manual wheel has become the favourite of professional potters as this provides the feel of the process of pottery better than the electric wheels.

\section{Electric Wheels}

An electric wheel is propelled by an electric motor, and has the advantage of not demanding any manual interference. Thus, when using this pottery wheel, the potter can concentrate completely on the work his hands are doing. However, it is to be acknowledged that for those who are very accustomed to the manual potter's wheel, the motion of the foot is hardly a hindrance to their work.. Some electric wheels have two fixed speeds, but most are connected to a foot pedal that allows the potter to control the wheel's speed through a range, usually 0-240 rpm. Electric wheels are lighter than kick wheels and some are fairly easy to move from one location to another, but if you need to frequently move your wheel from room to room or need true portability a tabletop wheel may be a better choice. (Specialty, 2013). These are by far the most popular throwing wheels because of their ease of operation whereby a slight movement of the foot on a pedal precisely controls the wheel head speed allowing the potter to concentrate on the throwing rather than the mechanics of the wheel (Clay Panel 2014). A key feature of the Electric Wheel is the continual duty motor. The $1 / 3 \mathrm{hp} \mathrm{motors}$ puts out more torque than most $1 / 2 \mathrm{hp}$ motors. Because the torque a wheel produces affects the amount of power you have to centre clay, this wheel provides you with more centring power. Each wheel has an industrial grade motor controller that controls speeds, senses the feedback from the motor, and provides constant torque through all speed ranges. This means the wheel will perform superbly at any speed.( Stuart, 2007). No doubt the electric wheels are superb, less stress of throwing, large amount of products in little time and lesser weight for mobility. This could be said of in a society that constantly enjoins electric power supply without interruption, as over dependence on the electric potter's wheel in a society without constant power supply amounts to deception and waste of time.

Motorized Kick Wheels combine some of the advantages of both an electric and kick wheel. Potter's have the option of kicking for fine speed control, while the electric motor makes it easier to centre large amounts of clay. Innovation has also made it possible that a two in one wheel is also currently in use. This could 
serve as a remedy to the challenge of "no zeal to work" that usually arises from the disappointment of power failure each time the electric wheels are in use in a depressed economy like nigeria.

\section{Advantages and Disadvantages of the Manual and Electric Wheels}

Both of these types of wheels have their advantages and disadvantages. Many people like to use kick wheels because it is easier to control speed for a beginner. Also, many people enjoy the "Zen" quality of pottery done on kick wheels. Kick wheels are also very tough and long lasting. The main problem with kick wheels is they are very expensive and heavy. Shipping a kick wheel can easily cost over $\$ 150$, even over $\$ 200$ ! Electric wheels are a little more difficult to use since they use a foot pedal to control the speed. Some electric wheels only have two selectable speeds. Good electric wheels have foot pedals that allow the artist to easily control the wheel head's speed. The major advantage of electric wheels is they are lighter. Some have been made for easy transport, by making them able to fit into a special plastic carrier a little bigger than a suitcase. (eBay Inc. 2014). The Electric potters wheels are usually lighter and smaller in size, throwing is faster, which is especially important in production work and many models are able to be transported. While the disadvantages are; reliance on electricity, can be noisy and inexperienced potters tend to increase rotational speed, which adversely affects the throw. The manual wheels are very low maintenance and will usually last a lifetime, many come with motors to assist with getting the flywheel to speed, easily allows for both counter-clockwise and clockwise rotation of the wheel head for both right-handed and left-handed throwing and for some potters, kick wheels gives a better "feel" for the throwing process. While the cons of the manual potters wheels are; extremely difficult to move and transport, injuries can occur if the flywheel is used as a step and long-term use may result in knee problems and aggravate arthritis. (About.com Pottery 2014). The advantages and disadvantages of the manual and electric potter's wheel have been a point of discursion and concern among ceramic professionals. This concern is even more of a concern to the ceramics artist in a developing society with electricity challenges and inconsistency. The pros and cons of both kinds of wheels are simplified below;

\section{Manual Wheels;}

\begin{tabular}{|c|c|c|}
\hline & Advantages & Disadvantages \\
\hline 1. & Easier to control speed for a beginner & Lacks the speed and strength to centre heavy clay \\
\hline 2. & Kick wheels are very tough and long lasting & They are very expensive and heavy \\
\hline 3. & The manual wheels are very low maintenance & \\
\hline 4. & $\begin{array}{l}\text { Easily allows for both counter-clockwise and clockwise rotation } \\
\text { of the wheel head for both right-handed and left-handed } \\
\text { throwing }\end{array}$ & $\begin{array}{l}\text { Injuries can occur if the flywheel is used as a step and long-term } \\
\text { use may result in knee problems and aggravate arthritis. }\end{array}$ \\
\hline 5. & Kick wheels gives a better "feel" for the throwing process & \\
\hline
\end{tabular}

\section{Electric Wheels;}

\begin{tabular}{|l|l|l|}
\hline & \multicolumn{1}{|c|}{ Advantages } & \multicolumn{1}{|c|}{ Disadvantages } \\
\hline 1. & $\begin{array}{l}\text { Throwing is faster, which is especially important in production } \\
\text { work }\end{array}$ & $\begin{array}{l}\text { Electric wheels are a little more difficult to use since they use a foot } \\
\text { pedal to control the speed. }\end{array}$ \\
\hline 2. & The major advantage of electric wheels is they are lighter & Reliance on electricity \\
\hline 3. & & Can be noisy and difficult to maintain when faulty \\
\hline 4. & & $\begin{array}{l}\text { Inexperienced potters tend to increase rotational speed, which } \\
\text { adversely affects the throw }\end{array}$ \\
\hline
\end{tabular}

In reviewing and comparing the Pros and cons of the manual and electric wheels, it is important to channel it to the objective of this research which intends to throw light on the manual wheels as the most appropriate for an economy such as ours. This comparison has shown that the electric wheel depend solely on electricity which is inimical to the society in question. The manual wheel from the above comparison will be more appropriate and this needs to be encouraged by ceramists.

\section{Conclusion}

Just like motor car that has both the manual and the automatic versions, and learners are most times advised to learn how to drive with a manual car so as to get well acquainted with the working principle of a vehicle. This advise is essential because the automatic vehicles no matter how excellent they feel, do not enable a learner the opportunity to know some basic working principles of a vehicle thereby brain washing the learner and makes it nearly impossible to drive the manual one when the automatic is not available.

Experience of separate pottery studios where the manual wheels are only used and also studios where both manual and electric wheel are both used shows that;

I. Potters that learnt how to throw with the manual wheels and got well acquainted with it are more hard working and more productive than potters that dwell only on the electric wheels in such a stat of epileptic power supply. 
II. Potters that are used to the manual wheels have gotten to know the working principles of the potter's wheel and when given the opportunity to use the electric wheel, handle it more professionally and more productively.

III. Using the electric potter's wheel as a starter in a situation of shortage of power supply brain washes and results in unproductivity. This is so because for a potter that is not used to the manual wheel, he or she becomes lazy and no zeal to work when electric power seizes and can't use the wheel until power is been restored.

IV. Due to the high speed and power most electric wheels are inclined to, it takes time to get use to working on it and also requires greater skill which most times comes out of mastery of the manual wheel.

\section{THE WAY FORWARD}

With the excellent nature of the electric wheels and it dependence solely on electric power, it is obvious that there is no need depending too much on it when there is a good alternative for maximum productivity. Out of much experiences of different usage of both wheels and for the sake of productivity, the researcher is of the opinion that;

- Beginners in the field should always be thought the art of throwing with the manual wheels so as to get them acquainted with the working principles of the manual wheels before exposing them to the electric wheels.

- Motorised kick wheels are also in operation now. This kind of two in one wheel could serve as remedy to the problem been addressed if ceramists can obtain this in their studios

- Effort by the government should be doubled in the drive towards constant electric power supply to enable industries work at less effort for maximum output

- Ceramic studios and workshops should place less emphasis on the electric wheels and put more emphasy on the manual wheels pending improvement in power supply in the country if improvement in the production of ceramics is to improve more than what it is now.

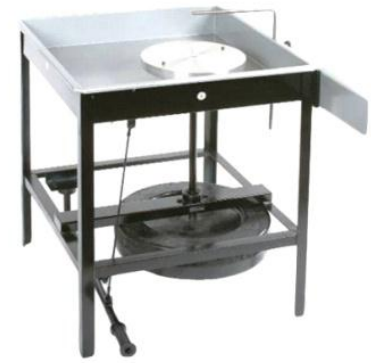

Fig. 1; Treadle Wheel

http://www.danielsmith.com/Item--i-848-020-010

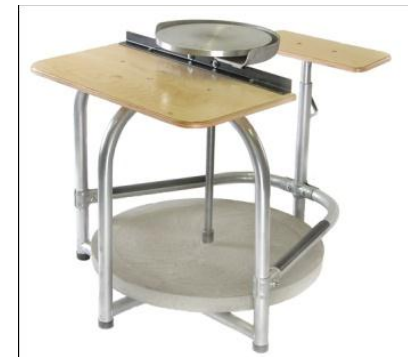

Fig. 2; Kick Wheel

http://www.continentalclay.com/detail.php?cat_id=194\&sub_categoryID=222\&PID=388 


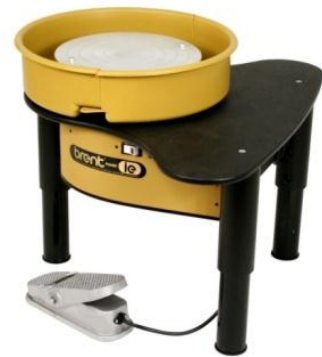

Fig. 3; Electric Wheel

http://www.amaco.com/wp/wp-content/uploads/2011/04/brent-model-ie-wheel-lrg.jpg

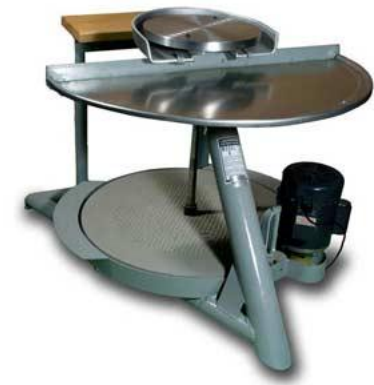

Fig. 4; Motorised Kick Wheel

http://www.axner.com/lockerbie-ek-kickwheel.aspx

\section{References}

[1]. About.com Pottery (2014) How to Buy a Potter's Wheel, retrieved 24 January 2014 http://pottery.about.com/od/potterswheels/tp/hbwheel.htm

[2]. Bryant V. (2013) The Origins of the Potter's Wheel, retrieved $11 \quad 2014$ http://www.ceramicstoday.com/articles/potters_wheel.htm

[3]. Clay Panel (2014) Wheels - Selecting One For You, retrieved 16 January 2014 http://shop.clay-planet.com/selectingwheel.aspx

[4]. Dodrill T. (2013) How to Make a Pottery Wheel, retrieved 9 January http://www.ehow.com/how_4926553_makepottery-wheel.html

[5]. eBay Inc. (2014) Pottery Wheels - Old, New, What's right for You, retrieved 20 January 2014 http://www.ebay.com/gds/Pottery-Wheels-Old-New-Whats-right-for-You /10000000000867407/g.html

[6]. Echeta C. (2011), Generating Stoneware Bricks for Stoneware Kilns in a Depressed Economy: The Rescue, Ashakwu Journal of Ceramics Vol. 8, Nigeria p.44.

[7]. Evans E. (2009) How to Make Pottery, retrieved 13 January 2014 http://www.art-craft-create-show.com/how_to_make_pottery.html

[8]. Gandon E. (2013), Regulating rotation speed in wheel throwing: Effects of mass and shape, retrieved 9

[9]. January 2014, http://www.academia.edu/4101339/Regulating rotation speed in wheel throwing Effectsof mass and shape

[10]. Gukas H.J. and Datiri Y.C. (2001), The Art of Pottery, published by C.C. communications, P.O. Box 6189, Jos. P. 34

[11]. Hellmold A. (2001) Potter's Wheel, Egypt, $2400 \quad$ BCE, retrieved $11 \quad$ January 2014 http://www.smith.edu/hsc/museum/ancient_inventions/potterwheel2.html

[12]. Jirousek C. (1995 ) Art, Design and Visual Thinking, retrieved $13 \quad$ January 2014 http://char.txa.cornell.edu/media/ceramic/ceramic.htm

[13]. Jones B (2010) kick wheels, retrieved 4 February 2014. Ceramic Publications Company content/uploads/2010/04/kickwheels.pdf

[14]. Mamza A.J. (2012) Factors involved in Ceramics and Interior Design in Nigeria Environment, Ashakwu Journal of Ceramics Vol. 9, Nigeria p.35.

[15]. Ortiz M. (2010) Pottery Production, retrieved 13 January $2014 \quad$ http://www.ortizpots.com/pottery/production.html

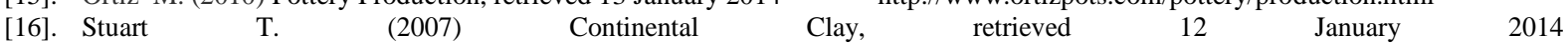
http://www.continentalclay.com/detail.php?cat_id=194\&sub_categoryID=69\&PID=391

[17]. Specialty S. (2013) Buying Guide - Potter's Wheels, retrieved $13 \quad$ January https://store.schoolspecialty.com/OA_HTML/xxssi_ibeDefaultCenter.jsp?type=IBE\&name=SAX_BUY_WH ELS\&minisite $=10206$ 